\title{
Biometry: a tool for the detection of amblyopia risk factor in children
}

\author{
Tsukasa Satou ${ }^{1,2}$ (D) Takahiro Niida ${ }^{1,2} \cdot$ Misae Ito $^{3}$ \\ Received: 28 February 2019 /Revised: 13 May 2019 / Accepted: 5 June 2019 / Published online: 10 June 2019 \\ (C) The Author(s) 2019
}

\begin{abstract}
Purpose To determine optical biometry data criteria for the detection of abnormal refraction in preschool children, and to evaluate the accuracy of these criteria for detecting amblyopia refractive risk factor (ARF), as defined in the 2013 guidelines of the American Association for Pediatric Ophthalmology and Strabismus (AAPOS).

Methods The present study included 200 eyes of 100 preschool children with normal eyes for the experimental determination of criteria and 142 eyes of 71 preschool children for validation of these criteria. Statistical data from normal eyes were used to determine both "high sensitivity failure criterion" and "high specificity failure criterion" associated with corneal astigmatism, interocular difference in axial length, and the prediction interval of a regression formula for predicting corneal power from axial length. Ophthalmological examination of children for validation included testing cycloplegic refraction and optical biometry testing. Outcomes from optical biometry criteria were compared with determination via ophthalmological examination, and the accuracy of the criteria for detecting ARF was evaluated.

Results Sensitivity of the "high sensitivity failure criterion" for detecting 2013 AAPOS ARF was $100 \%$, while the specificity was $80.5 \%$. The sensitivity of the "high specificity failure criterion" was $93.3 \%$, while the specificity was $95.1 \%$.

Conclusions The criteria derived from optical biometry data in this study exhibited excellent sensitivity and specificity for detecting ARF. This study may lead to a new approach to vision screening in preschool children.
\end{abstract}

Keywords Vision screening $\cdot$ Optical biometry $\cdot$ Axial length $\cdot$ Corneal power $\cdot$ Sensitivity $\cdot$ Specificity

\section{Introduction}

Amblyopia is a condition that emerges when a child's visual system does not develop properly, resulting in abnormal vision in one or both eyes [1,2]. Anisometropic, strabismic, and ametropic (bilateral high hyperopia and myopia or astigmatism) amblyopia are commonly found in the general population. Pure anisometropic and bilateral ametropic amblyopia do not demonstrate clear ocular misalignment, rendering their detection difficult. It is widely accepted that the optimal time to correct

Tsukasa Satou

tsukasa@iuhw.ac.jp

1 Department of Orthoptics and Visual Sciences, School of Health Sciences, International University of Health and Welfare, Tochigi, Japan

2 Department of Orthoptics and Visual Sciences, Doctoral Program in Health Sciences, Graduate School of Health and Welfare Sciences, International University of Health and Welfare Graduate School, Tochigi, Japan

3 Eye Center, Sanno Hospital, Tokyo, Japan amblyopia is during infancy or early childhood, before the visual system, including the visual pathway from the retina to the brain, has fully matured [3-8]. Therefore, vision screening to detect amblyopia at a sufficiently early age to enable successful treatment has been strongly recommended worldwide [9-11].

Refraction testing by handheld autorefractor or photorefractor is a useful tool for detecting amblyopia or significant refractive errors [12] during vision screening. Atkinson J et al. first explored the utility of refraction testing using a photorefractor in vision screening [13, 14]. Recently, a handheld photo-refractor with software for the detection of abnormal refraction (i.e., the type that may cause amblyopia) has become commercially available [15-18] that reportedly reduce the effects of accommodation on refraction, relative to those encountered when using conventional handheld autorefractors that require patients to gaze into a target inside the instrument [19]. However, autorefractors (including the photorefractor) cannot completely eliminate the effects of accommodation on refraction without the use of cycloplegics.

Optical biometry devices can measure corneal power and axial length, without the adverse effects of accommodation. Corneal power and axial length are closely associated with 
refraction and can partially explain refraction using a regression formula [20, 21]. In this respect, Borchert et al. [22] reported that axial length could be tested using the IOL Master (Carl Zeiss Meditec, Jena, Germany) in nearly all children by the of age 36 months in a population-based sample of preschool children in the USA. Huang et al. [23] reported testability values of the IOL Master in 3-year-old children of 93.7\% for axial length and $78.6 \%$ for corneal power overall; both measures improved with age. Based on these findings, an approach for vision screening that uses an optical biometry device may be useful for effectively detecting abnormal refraction in preschool children. To the best of our knowledge, there have been no studies focused on the accuracy of optical biometry devices, with respect to the detection of abnormal refraction. The present study aimed to identify criteria derived from optical biometry data that could be used to detect abnormal refraction, and to evaluate the accuracy of these criteria for detecting amblyopia refractive risk factor (ARF), as defined by the 2013 report of the American Association for Pediatric Ophthalmology and Strabismus (AAPOS) Vision Screening Committee (Table 1) [24].

\section{Methods}

\section{Participants}

The procedures used in the present study were prospectively approved by the Institutional Review Board of the International University of Health and Welfare in Tochigi, Japan (approval numbers: 17-Io-23, 18-Io-5, and 13-B-298), and conformed to the tenets of the Declaration of Helsinki. Informed consent was obtained from each of the participants' guardians following an explanation of the purpose, risks, potential discomfort, and procedures associated with the study.

The study included 200 eyes of 100 preschool children with normal eyes ( 45 boys and 55 girls, mean age: $63.3 \pm$ 6.3 months, range: 52-76 months) in the reference group, and 142 eyes of 71 preschool children ( 37 boys and 34 girls, mean age: $61.9 \pm 16.3$ months, range: $25-84$ months) in the validation group. The reference group was recruited during vision screening; the inclusion criteria for that group were an uncorrected visual acuity of $0.00 \log$ MAR or better for distant

Table 1 Amblyopia refractive risk factor (cycloplegic refraction)

\begin{tabular}{lllll}
\hline Age (months) & Astigmatism & Hyperopia & Anisometropia & Myopia \\
\hline $12-30$ & $>2.0 \mathrm{D}$ & $>4.5 \mathrm{D}$ & $>2.5 \mathrm{D}$ & $>-3.5 \mathrm{D}$ \\
$31-48$ & $>2.0 \mathrm{D}$ & $>4.0 \mathrm{D}$ & $>2.0 \mathrm{D}$ & $>-3.0 \mathrm{D}$ \\
$>48$ & $>1.5 \mathrm{D}$ & $>3.5 \mathrm{D}$ & $>1.5 \mathrm{D}$ & $>-1.5 \mathrm{D}$ \\
\hline
\end{tabular}

$D$, diopters
( $5 \mathrm{~m})$ and near vision $(1 / 3 \mathrm{~m}), 60$ arcseconds or better in stereopsis, and no strabismus or history of wearing spectacles. The validation group was recruited from among patients who visited the International University of Health and Welfare Hospital in Tochigi, Japan, with or without abnormal refraction or amblyopia. Subjects were excluded from the study if they had a history of eye or head injuries, intraocular surgery, or ocular pathology.

\section{Optical biometry measurement in the reference group and determination of criteria values}

In the reference group, mean corneal power, corneal astigmatism, and axial length of both eyes were measured using the AL-Scan (NIDEK Co., Ltd., Aichi, Japan). Based on the resulting grouped data, criterion values were determined for corneal astigmatism, absolute interocular difference in axial length, and the prediction interval of a regression formula for the prediction of corneal power from axial length. Kolmogorov-Smirnov tests were used to determine whether these parameters were normally distributed. Criterion values were defined by the 95th and 99th percentiles in corneal astigmatism and the interocular difference in axial length and the 95\% and $99 \%$ prediction intervals in the regression formula. Corneal astigmatism criteria were expected to detect astigmatism in ARF. Interocular difference in axial length was expected to detect anisometropia, and the prediction interval of the regression formula for the prediction of corneal power from axial length was expected to detect both abnormal hyperopia and myopia.

\section{Optical biometry measurement in the validation group and validation of accuracy of criterion values for detecting amblyopia refractive risk factor}

Ophthalmological examination was performed, including testing of cycloplegic refraction and optical biometry, in the validation group. Mean corneal power, corneal astigmatism, and axial length in both eyes were measured using an IOL Master 500 (Carl Zeiss Meditec). Based on the determination criteria, the patients were classified as "positive (out of criteria)" or "negative (within criteria)." Cycloplegic refraction was performed after instillation of $1 \%$ atropine every morning and night for 1 week or after instillation of $1 \%$ cyclopentolate three times every $5 \mathrm{~min}$. Based on cycloplegic refraction, patients were classified as "ARF+" or "ARF-," with reference to the definition of ARF described in the AAPOS guidelines.

Sensitivity, specificity, positive predictive values (PPVs), and negative predictive values (NPVs) of the criteria pertaining to the detection of ARF were calculated. PPV and NPV are affected by the prevalence of disease in the specific population being studied, yet they can be estimated for the general population via a diagnostic test with fixed sensitivity 
and specificity. The assumption of fixed sensitivity and specificity implies that the diagnostic test is generalizable to the broader population. Thus, the probability that the test will correctly predict that an individual is disease-positive (or disease-negative) is the same, regardless of whether they are a member of a population of children at a doctor's office or a member of the general population. If this assumption is valid, PPVs and NPVs incorporating the prevalence of a given disease in a population can be estimated using sensitivity and specificity, in accordance with the relationships represented in the formulae below $[25,26]$.

Estimated PPV $=\frac{\text { sensitivity } \times \text { prevalence }}{\text { sensitivity } \times \text { prevalence }+(1-\text { specificity }) \times(1-\text { prevalence })}$

Estimated NPV $=\frac{\text { specificity } \times(1-\text { prevalence })}{\text { specificity } \times(1-\text { prevalence })+(1-\text { Sensitivity }) \times \text { prevalence }}$

As prevalence decreases, PPV is expected to decrease, while NPV is expected to increase. Using the relationships represented above, we estimated the PPV and NPV of the criteria in a general population of preschool children.

\section{Results}

\section{Determination of criteria values}

The distributions of corneal power, corneal astigmatism, axial length, and interocular difference in axial length in the reference group are shown in Fig. 1 and Table 2. Classifications of "high sensitivity failure criterion" and "high specificity failure criterion" were determined based on statistical data derived from the reference group (Table 3). The criteria denoting "high sensitivity failure criterion" were $2.15 \mathrm{D}$ for corneal astigmatism, $0.25 \mathrm{~mm}$ for absolute interocular difference in axial length, and a $95 \%$ prediction interval in the regression formula $\left(y=-1.82 x+84.23\right.$ with $R^{2}=0.69, x$ is axial length, $y$ is corneal power) (Fig. 2), these may produce a false-positive result. The criteria denoting "high specificity failure criterion" were $2.81 \mathrm{D}$ for corneal astigmatism, $0.41 \mathrm{~mm}$ for absolute interocular difference in axial length, and a $99 \%$ prediction interval in the regression formula (Fig. 2), these may produce a false-negative result.

\section{Validation of detection accuracy of criteria for detecting the 2013 American Association for Pediatric Ophthalmology and Strabismus amblyopia refractive risk factor}

In the validation group, the patients were classified as "negative (within criteria)" for either the high sensitivity failure criterion or the high specificity failure criterion if they met the criteria for all of the following 3 items: corneal astigmatism, interocular difference in axial length, and prediction interval in the regression formula. In contrast, the patients were classified as "positive (out of criteria)" if they did not meet the criteria for any of these 3 items. Detection accuracy is shown in Table 4. The sensitivity of the "high sensitivity failure criterion" for the detection of ARF as defined by the 2013 AAPOS was $100 \%$ (95\% confidence interval (CI), $88.4 \%-$ $100 \%$ ), and the specificity was $80.5 \%$ (95\% CI, $64.9 \%-$ 91.4\%). The prevalence of ARF in the validation group in the current study was $42.3 \%$, the PPV was $78.9 \%$ (95\% CI, $62.7 \%-90.5 \%$ ), and the NPV was $100 \%$ (95\% CI, $89.4 \%-$ $100 \%$ ). Arnold [27] estimated that the prevalence of ARF associated with refraction in the general preschool population was $15 \%$. Based on a prevalence of $15 \%$, the respective PPV and NPV values in a general preschool population were estimated to be $47.5 \%$ and $100 \%$. The sensitivity of the "high specificity failure criterion" to detect ARF was $93.3 \%$ (95\% CI, $77.9 \%-99.2 \%$ ), while its specificity was $95.1 \%$ (95\% CI, $82.6 \%-99.6 \%$ ), the PPV was $93.3 \%$ (95\% CI, 77.9\%-99.2\%) and the NPV was $95.1 \%$ (95\% CI, 82.6\%-99.6\%). The respective PPV and NPV values in a general population of preschool children were estimated to be $77.1 \%$ and $98.8 \%$, respectively. The detection accuracies of each refractive subtype are shown in Table 5. The prevalence of astigmatism, hyperopia, and myopia in this study, based on ARF in the validation group, were $12.7 \%, 16.2 \%$, and $8.5 \%$ of 142 eyes, respectively; the prevalence of anisometropia was $15.5 \%$ of 71 patients. The "high sensitivity failure criterion" exhibited high sensitivity, while the "high specificity failure criterion" exhibited high specificity, for the refractive error of any subtype.

\section{Discussion}

The criteria generated in the current study exhibited excellent ability to detect ARF. Total astigmatism was found to be primarily driven by corneal component in several earlier studies [28-30]. Shankar and Bobier [30] investigated the 

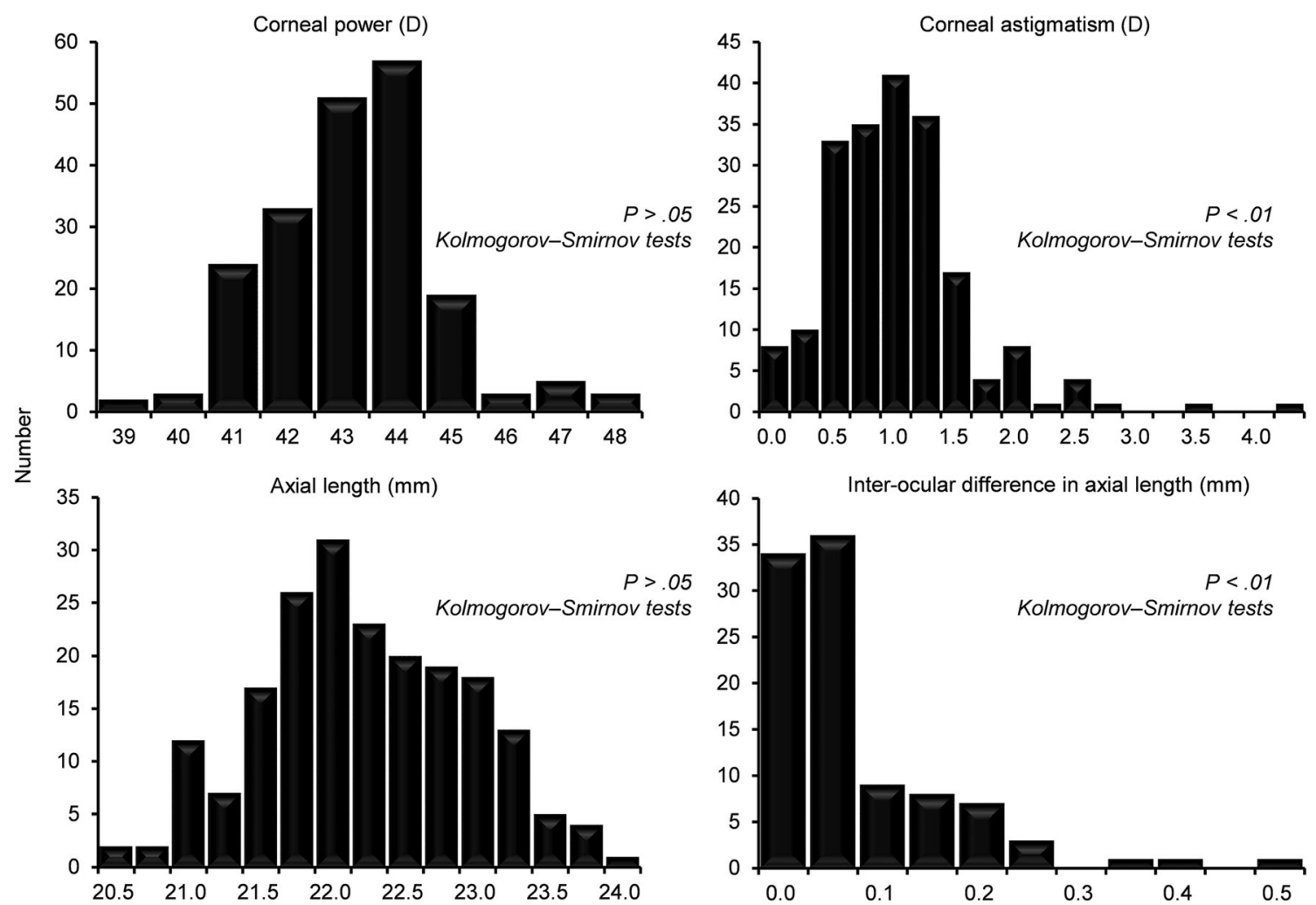

Fig. 1 Histogram of corneal power, corneal astigmatism, axial length, and interocular difference in axial length in the reference group. D, diopter; mm, millimeter

contributions of corneal and lenticular components to total astigmatism in preschool children. They concluded that astigmatism is mainly corneal in children aged 3-5 years and that there is no lenticular compensation for high levels of corneal astigmatism in the eyes of preschool-aged children. Moreover, associations between ocular biometry findings and anisometropia have been demonstrated in a few earlier studies [31-34]; axial length is strongly correlated with anisometropia. Huynh et al. [33] investigated associations in 6-year-olds and reported that the interocular difference in axial length contributed to anisometropia, while the difference in corneal power dose did not. Thus, in children aged approximately 6 years, the degree of anisometropia may depend strongly on differences in axial length. Therefore, the detection of total astigmatism and anisometropia through parameters pertaining to corneal astigmatism and interocular differences in axial length is a rational approach. Relationships among corneal power, axial length, and refraction have been reported in several earlier studies [35-37], and AL/ $\mathrm{CR}$ ratio (i.e., the value of axial length divided by corneal curvature radius) is strongly correlated with cycloplegic refraction.

Table 2 Distribution in the reference group

\begin{tabular}{lllll}
\hline & Corneal power (D) & Corneal astigmatism (D) & Axial length (mm) & $\begin{array}{l}\text { Inter-ocular difference } \\
\text { in axial length (mm) }\end{array}$ \\
\hline $\begin{array}{l}P \text { value for normal distribution } \\
\text { Mean }\end{array}$ & $>0.10$ & $<0.01$ & $>0.10$ & $<0.01$ \\
Standard deviation & 43.67 & 1.13 & 22.33 & 0.09 \\
Range & 1.57 & 0.59 & 0.72 & 0.09 \\
95\% prediction interval & $39.44-48.29$ & $0.06-4.47$ & $20.52-24.03$ & $0.00-0.52$ \\
99\% prediction interval & $40.58-46.75$ & - & $20.92-23.74$ & - \\
Median & $39.60-47.73$ & - & $20.47-24.18$ & - \\
5-95 percentile & 43.68 & 1.06 & 22.28 & 0.07 \\
1-99 percentile & $41.22-46.16$ & $0.36-2.15$ & $21.16-23.49$ & $0.00-0.25$ \\
\hline
\end{tabular}

$D$, diopters; $m m$, millimeter 
Table 3 Two criterion for detecting abnormal refraction using axial length and corneal power

\begin{tabular}{lll}
\hline & $\begin{array}{l}\text { High sensitivity failure } \\
\text { criterion }\end{array}$ & $\begin{array}{l}\text { High specificity failure } \\
\text { criterion }\end{array}$ \\
\hline Corneal astigmatism & $>2.15 \mathrm{D}$ & $>2.81 \mathrm{D}$ \\
Inter-ocular difference in axial length & $>0.25 \mathrm{~mm}$ & $>0.41 \mathrm{~mm}$ \\
Relationship between axial length and corneal power & $95 \%$ prediction interval & $99 \%$ prediction interval \\
\hline
\end{tabular}

$D$, diopters; $m m$, millimeter
Thus, an abnormal relationship between corneal power and axial length indicates abnormal refraction. In this study, a patient was suspected to have abnormal myopia, when the plot derived from corneal power and axial length exceeded the upper limit of the prediction interval in the regression formula, while the patient was suspected to have abnormal hypertropia, when the plot derived from corneal power and axial length exceeded the lower limit of the prediction interval in the regression formula. Therefore, the examiner may be able to screen for abnormal refraction based on the relationship between corneal power and axial length, without the need for calculation of the $\mathrm{AL} / \mathrm{CR}$ ratio using the chart, as shown in Fig. 2. Guo et al. [36] investigated the $\mathrm{AL} / \mathrm{CR}$ ratio in children aged 3-6 years and reported that the differences related to age and sex were marginal. This means that differences related to age and sex in the regression formula for the prediction of corneal power from axial length were also marginal. Therefore, the detection of ametropia (i.e., abnormal hypertropia or myopia) based on relationships between corneal power and axial length is a rational approach. Furthermore, the accuracy of this approach can be potentially improved by optimizing the criteria to be age-specific.

The estimated NPV in the general population was $100 \%$ based on the "high sensitivity failure criterion," and the estimated PPV was $77.1 \%$ based on the "high specificity failure

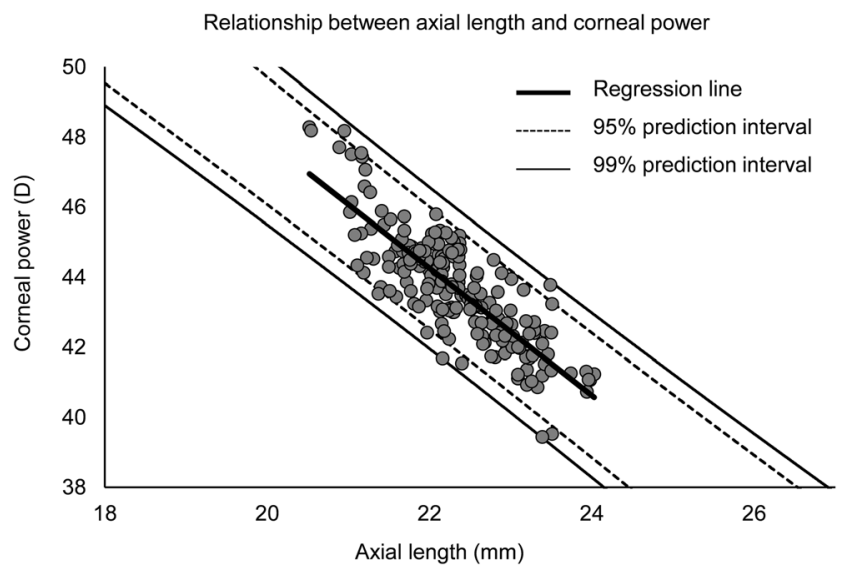

Fig. 2 Relationship between axial length and corneal power in the reference group. Axial length was regarded as the explanatory variable ( $x$ axis), and corneal power was regarded as the criterion variable ( $y$ axis). The regression formula for predicting corneal power based on axial length was $y=-1.82 x+84.23$ (determination coefficient 0.69). $\mathrm{D}$, diopter; $\mathrm{mm}$, millimeter criterion." There is a strong possibility that ARF may be absent when the high sensitivity failure criterion is not met, while it may be present when the "high specificity failure criterion" is met. The prevalence of ARF in the current study population was $42.3 \%$. This differed notably from the prevalence of the general preschool population. Moreover, refractive errors in patients with ARF in the study population may be relatively severe, compared with those in patients with ARF in the general population. The estimated PPV and NPV in the present study may not be based on a valid assumption. Therefore, we plan to validate both the PPV and NPV values in a future study in the general preschool population.

The study had a few limitations. Refraction with cycloplegia was not considered in the reference group. Children with mild myopia of less than $1.50 \mathrm{D}$ may have been excluded from the reference group. Guo et al. [36] reported that the prevalence of myopia was $0 \%$ at 3 years of age and $3.7 \%$ at 6 years of age. This fact may not have had a substantial effect on the present results. However, detection criteria, defined on the basis of cycloplegic refraction in children without ARF, may enable better differentiation between children with and without ARF. Another limitation is that cycloplegic refraction was measured by 2 different methods in the validation group (atropine for 1 week or cyclopentolate, three times, in the clinic). A few children might have been classified as "ARF+" owing to cycloplegic refraction with atropine, which led to a decrease in the false-positive or an increase in the false-negative results. According to earlier reports [38], mean difference of cycloplegic refraction between atropine and cyclopentolate was $0.40 \mathrm{D}$ in children (3-5 years of age) with hyperopia of more than $1.00 \mathrm{D}$. This may have had only a marginal effect on the results of the present study. Finally, different biometric instruments were used for the reference and validation groups. Children in the reference group were assessed during vision screening. Thus, we selected the ALscan, which is easy to transport and set up. However, according to earlier reports [39-41], axial length and keratometry (corneal power) measured by the AL-scan was not significantly different from that measured by IOL Master, and good concurrence was found between both devices. Thus, this may not have had a substantial effect on the results of this study.

Furthermore, a disadvantage of this technique is that it currently cannot detect large amblyogenic refractive errors 
Table 4 Detection accuracy of criterion for detecting the 2013 AAPOS ARF

\begin{tabular}{|c|c|c|c|c|c|c|}
\hline & $\mathrm{ARF}+$ & ARF- & Sensitivity $(95 \% \mathrm{CI})$ & Specificity $(95 \% \mathrm{CI})$ & PPV $(95 \% \mathrm{CI})$ & NPV $(95 \%$ CI $)$ \\
\hline \multicolumn{7}{|c|}{ High sensitivity failure criterion } \\
\hline Positive (out of criteria) & 30 & 8 & $100(88.4-100)$ & $80.5(64.9-91.4)$ & $78.9(62.7-90.5)$ & $100(89.4-100)$ \\
\hline Negative (within criteria) & 0 & 33 & & & & \\
\hline \multicolumn{7}{|c|}{ High specificity failure criterion } \\
\hline Positive (out of criteria) & 28 & 2 & $93.3(77.9-99.2)$ & $95.1(82.6-99.6)$ & $93.3(77.9-99.2)$ & $95.1(82.6-99.6)$ \\
\hline Negative (within criteria) & 2 & 39 & & & & \\
\hline
\end{tabular}

$A R F$, amblyopia risk factors; $C I$, confidence interval; $N P V$, negative predictive value; $P P V$, positive predictive value

caused by lenticular abnormalities [42] (e.g., cataract, posterior lenticonus, and Marfan syndrome). Although these situations are rare, it is essential to consider this disadvantage if this technique is to be used in the future.
Earlier studies have not focused on the accuracy of an optical biometry device for detecting abnormal refraction. This study may lead to a new approach to vision screening. Future studies with larger sample sizes are needed.

Table 5 Detection accuracy each refractive subtype of criterion for detecting the 2013 AAPOS ARF

\begin{tabular}{|c|c|c|c|c|c|c|}
\hline & $\mathrm{ARF}+$ & ARF- & Sensitivity (95\% CI) & Specificity $(95 \%$ CI) & PPV $(95 \% \mathrm{CI})$ & NPV (95\% CI) \\
\hline \multicolumn{7}{|l|}{ Astigmatism (142 eyes) } \\
\hline \multicolumn{7}{|l|}{ High sensitivity failure criterion } \\
\hline Positive (out of criteria) & 15 & 14 & $83.3(57.7-97.1)$ & $88.7(81.8-93.7)$ & $51.7(32.4-70.8)$ & $97.3(92.4-99.5)$ \\
\hline Negative (within criteria) & 3 & 110 & & & & \\
\hline \multicolumn{7}{|c|}{ High specificity failure criterion } \\
\hline Positive (out of criteria) & 13 & 3 & $72.2(46.3-90.3)$ & $97.6(92.8-99.6)$ & $81.3(54.4-96.0)$ & $96.0(90.8-98.8)$ \\
\hline Negative (within criteria) & 5 & 121 & & & & \\
\hline \multicolumn{7}{|l|}{ Hyperopia (142 eyes) } \\
\hline \multicolumn{7}{|c|}{ High sensitivity failure criterion } \\
\hline Positive (out of criteria) & 21 & 6 & $91.3(72.0-98.9)$ & $95.0(89.4-98.1)$ & $77.8(57.4-91.8)$ & $98.3(93.9-99.8)$ \\
\hline Negative (within criteria) & 2 & 113 & & & & \\
\hline \multicolumn{7}{|c|}{ High specificity failure criterion } \\
\hline Positive (out of criteria) & 17 & 3 & $73.9(51.6-89.8)$ & $97.5(92.8-99.5)$ & $85.0(62.1-96.8)$ & $95.1(89.6-98.2)$ \\
\hline Negative (within criteria) & 6 & 116 & & & & \\
\hline \multicolumn{7}{|l|}{ Anisometropia (71 patients) } \\
\hline \multicolumn{7}{|c|}{ High sensitivity failure criterion } \\
\hline Positive (out of criteria) & 11 & 5 & $100(71.5-100)$ & $91.7(81.6-97.2)$ & $68.8(41.3-89.0)$ & $100(93.5-100)$ \\
\hline Negative (within criteria) & 0 & 55 & & & & \\
\hline \multicolumn{7}{|c|}{ High specificity failure criterion } \\
\hline Positive (out of criteria) & 11 & 2 & $100(71.5-100)$ & $96.7(87.8-99.8)$ & $84.6(54.6-98.1)$ & $100(93.8-100)$ \\
\hline Negative (within criteria) & 0 & 58 & & & & \\
\hline \multicolumn{7}{|l|}{ Myopia (142 eyes) } \\
\hline \multicolumn{7}{|c|}{ High sensitivity failure criterion } \\
\hline Positive (out of criteria) & 11 & 5 & $91.7(61.3-99.8)$ & $96.2(91.1-98.8)$ & $68.8(41.3-89.0)$ & $99.2(95.2-100)$ \\
\hline Negative (within criteria) & 1 & 125 & & & & \\
\hline \multicolumn{7}{|c|}{ High specificity failure criterion } \\
\hline Positive (out of criteria) & 8 & 0 & $66.7(34.3-90.1)$ & $100(97.2-100)$ & $100(63.1-100)$ & $97.0(92.3-99.3)$ \\
\hline Negative (within criteria) & 4 & 130 & & & & \\
\hline
\end{tabular}

$A R F$, amblyopia risk factors; $C I$, confidence interval; $N P V$, negative predictive value; $P P V$, positive predictive value 
Funding This work was supported by JSPS KAKENHI Grant Number JP17K13249.

\section{Compliance with ethical standards}

Conflict of interest The authors declare that they have no conflict of interest.

Ethical approval All procedures performed in studies involving human participants were in accordance with the ethical standards of the institutional and/or national research committee and with the 1964 Helsinki declaration and its later amendments or comparable ethical standards.

Informed consent Informed consent was obtained from all individual participants included in the study.

Open Access This article is distributed under the terms of the Creative Commons Attribution 4.0 International License (http:// creativecommons.org/licenses/by/4.0/), which permits unrestricted use, distribution, and reproduction in any medium, provided you give appropriate credit to the original author(s) and the source, provide a link to the Creative Commons license, and indicate if changes were made.

\section{References}

1. Awaya S, Miyake S (1988) Form vision deprivation amblyopia: further observations. Graefes Arch Clin Exp Ophthalmol 226: 132-136

2. Awaya S, Watanabe Y (1995) Amblyopia. Curr Opin Ophthalmol 6(5):9-14

3. Holmes JM, Beck RW, Kraker RT et al (2003) Impact of patching and atropine treatment on the child and family in the amblyopia treatment study. Arch Ophthalmol 121(11):1625-1632. https://doi. org/10.1001/archopht.121.11.1625

4. Cotter SA; Pediatric Eye Disease Investigator Group, Edwards AR, et al (2006) Treatment of anisometropic amblyopia in children with refractive correction. Ophthalmology 113(6):895-903. https://doi. org/10.1016/j.ophtha.2006.01.068

5. Kuman IG, Fedorov SN, Novikova LA (1983) The sensitive period in the development of the human visual system. Zh Vyssh Nerv Deiat Im I P Pavlova 33(3):434-441

6. Awaya S, Sugawara M, Miyake S (1979) Observations in patients with occlusion amblyopia: results of treatment. Trans Ophthalmol Soc U K 99(3):447-454

7. Epelbaum M, Milleret C, Buisseret P, Dufier JL (1993) The sensitive period for strabismic amblyopia in humans. Ophthalmology 100(3):323-327

8. Hardman Lea SJ, Loades J, Rubinstein MP (1989) The sensitive period for anisometropic amblyopia. Eye 3(6):783-790. https://doi. org/10.1038/eye.1989.122

9. Ciner EB, Schmidt PP, Orel-Bixler D et al (1998) Vision screening of preschool children: evaluating the past, looking toward the future. Optom Vis Sci 75(8):571-584

10. U Eibschitz-Tsimhoni M, Friedman T, Naor J, Eibschitz N, Friedman Z (2000) Early screening for amblyogenic risk factors lowers the prevalence and severity of amblyopia. J AAPOS 4(4): 194-199. https://doi.org/10.1067/mpa.2000.105274

11. Satou T, Takahashi Y, Ito M, Mochizuki H, Niida T (2018) Evaluation of visual function in preschool-age children using a vision screening protocol. Clin Ophthalmol 12:339-344. eCollection 2018. https://doi.org/10.2147/OPTH.S160288
12. Schmidt P, Maguire M, Dobson V et al (2004) Comparison of preschool vision screening tests as administered by licensed eye care professionals in the vision in preschoolers study. Ophthalmology 111(4):637-650. https://doi.org/10.1016/j.ophtha.2004.01.022

13. Atkinson J, Braddick O (1983) The use of isotropic photorefraction for vision screening in infants. Acta Ophthalmol Suppl 157:36-45

14. Atkinson J, Braddick O, Robier B et al (1996) Two infant vision screening programmes: prediction and prevention of strabismus and amblyopia from photo- and videorefractive screening. Eye (Lond) 10(2):189-198. https://doi.org/10.1038/eye.1996.46

15. Peterseim MM, Papa CE, Wilson ME et al (2014) The effectiveness of the spot vision screener in detecting amblyopia risk factors. J AAPOS 18(6):539-542. https://doi.org/10.1016/j.jaapos.2014.07.176

16. Arana Mendez M, Arguello L, Martinez J et al (2015) Evaluation of the spot vision screener in young children in Costa Rica. J AAPOS 19(5):441-444. https://doi.org/10.1016/j.jaapos.2015.08.002

17. Marzolf AL, Peterseim MM, Forcina BD et al (2017) Use of the spot vision screener for patients with developmental disability. J AAPOS 21(4):313-315. https://doi.org/10.1016/j.jaapos.2017.04.008

18. Forcina BD, Peterseim MM, Wilson ME et al (2017) Performance of the spot vision screener in children younger than 3 years of age. Am J Ophthalmol 178:79-83. https://doi.org/10.1016/j.ajo.2017. 03.014

19. Teberik K, Eski MT, Kaya M, Ankarall H (2018) A comparison of three different photoscreeners in children. J Pediatr Ophthalmol Strabismus 55(5):306-311. https://doi.org/10.3928/0191391320180405-03

20. Khan AO (2011) The relationships among cycloplegic refraction, keratometry, and axial length in children with refractive accommodative esotropia. J AAPOS 15(3):241-244. https://doi.org/10.1016/ j.jaapos.2011.01.157

21. Khan AO (2012) The relationship of axial length to cycloplegic refraction and keratometry in amblyopic eyes of hyperopic children. J AAPOS 16(1):46-48. https://doi.org/10.1016/j.jaapos. 2011.10.006

22. Borchert M, Wang Y, Tarczy-Hornoch K (2008) Testability of the Retinomax autorefractor and IOLMaster in preschool children: the Multi-ethnic Pediatric Eye Disease Study. Ophthalmology 115(8): 1422-1425. https://doi.org/10.1016/j.ophtha.2007.10.036

23. Huang D, Chen X, Gong Q et al (2016) Ocular biometric parameters among 3-year-old Chinese children: testability, distribution and association with anthropometric parameters. Sci Rep 6:29577. https://doi.org/10.1038/srep29577

24. Donahue SP, Arthur B, Neely DE et al (2013) Guidelines for automated preschool vision screening: a 10-year, evidence-based update. J AAPOS 17(1):4-8. https://doi.org/10.1016/j.jaapos.2012. 09.012

25. Altman DG, Bland JM (1994) Statistics notes: diagnostic tests 1: sensitivity and specificity. BMJ 308(6943): 1552

26. Altman DG, Bland JM (1994) Statistics notes: diagnostic tests 2: predictive values. BMJ 309(6947): 102

27. Arnold RW (2013) Amblyopia risk factor prevalence. J Pediatr Ophthalmol Strabismus 50(4):213-217. https://doi.org/10.3928/ 01913913-20130326-01

28. Howland HC, Sayles N (1985) Photokeratometric and photorefractive measurements of astigmatism in infants and young children. Vis Res 25(1):73-81

29. Dobson V, Miller JM, Harvey EM (1999) Corneal and refractive astigmatism in a sample of 3- to 5-year-old children with a high prevalence of astigmatism. Optom Vis Sci 76(12):855-860

30. Shankar S, Bobier WR (2004) Corneal and lenticular components of total astigmatism in a preschool sample. Optom Vis Sci 81(7): 536-542

31. Tong L, Saw SM, Chia KS, Tan D (2004) Anisometropia in Singapore school children. Am J Ophthalmol 137(3):474-479. https://doi.org/10.1016/j.ajo.2003.10.028 
32. Wu HM, Casson RJ, Newland HS, Muecke J, Selva D, Aung T (2008) Anisometropia in an adult population in rural Myanmar: the Meiktila Eye Study. Ophthalmic Epidemiol 15(3):162-166. https:// doi.org/10.1080/09286580701843796

33. Huynh SC, Wang XY, Ip J et al (2006) Prevalence and associations of anisometropia and aniso-astigmatism in a population based sample of 6 year old children. Br J Ophthalmol 90(5):597-601. https:// doi.org/10.1136/bjo.2005.083154

34. Hashemi H, Khabazkhoob M, Emamian MH, Shariati M, Abdolahi-nia T, Fotouhi A (2013) All biometric components are important in anisometropia, not just axial length. Br J Ophthalmol 97(12):1586-1591. https://doi.org/10.1136/bjophthalmol-2013303939

35. Foo VH, Verkicharla PK, Ikram MK et al (2016) Axial length/ corneal radius of curvature ratio and myopia in 3-year-old children. Transl Vis Sci Technol 5(1):5. eCollection 2016. https://doi.org/10. $1167 /$ tvst.5.1.5

36. Guo X, Fu M, Ding X, Morgan IG, Zeng Y, He M (2017) Significant axial elongation with minimal change in refraction in 3- to 6-year-old Chinese preschoolers: the Shenzhen Kindergarten Eye Study. Ophthalmology 124(12):1826-1838. https://doi.org/10. 1016/j.ophtha.2017.05.030

37. Jong M, Sankaridurg P, Naduvilath TJ, Li W, He M (2018) The relationship between progression in axial length/corneal radius of curvature ratio and spherical equivalent refractive error in myopia. Optom Vis Sci 95(10):921-929. https://doi.org/10.1097/OPX. 0000000000001281
38. Farhood QK (2012) Cycloplegic refraction in children with cyclopentolate versus atropine. J Clin Exp Ophthalmol 3(7):239. https://doi.org/10.4172/2155-9570.1000239

39. Kaswin G, Rousseau A, Mgarrech M, Barreau E, Labetoulle M (2014) Biometry and intraocular lens power calculation results with a new optical biometry device: comparison with the gold standard. J Cataract Refract Surg 40(4):593-600. https://doi.org/10.1016/j.jcrs. 2013.09.015

40. Huang J, Savini G, Li J et al (2014) Evaluation of a new optical biometry device for measurements of ocular components and its comparison with IOLMaster. Br J Ophthalmol 98(9):1277-1281. https://doi.org/10.1136/bjophthalmol-2014-305150

41. Suto C, Shimamura E, Watanabe I (2015) Comparison of 2 optical biometers and evaluation of the Camellin-Calossi intraocular lens formula for normal cataractous eyes. J Cataract Refract Surg 41(11): 2366-2372. https://doi.org/10.1016/j.jcrs.2015.04.032

42. Khokhar S, Agarwal T, Kumar G, Kushmesh R, Tejwani LK (2012) Lenticular abnormalities in children. J Pediatr Ophthalmol Strabismus 49(1):32-37. https://doi.org/10.3928/0191391320110614-01

Publisher's note Springer Nature remains neutral with regard to jurisdictional claims in published maps and institutional affiliations. 